\title{
Understanding the Development of the Universal Declaration on Bioethics and Human Rights
}

\author{
Russell D'Souza ${ }^{1}$, Mary Mathew ${ }^{2}$ \\ ${ }^{1}$ Head Asia Pacific Division UNESCO Chair in Bioethics, (Haifa), Melbourne, Australia. \\ ${ }^{2}$ Head Indian Program UNESCO Chair in Bioethics, (Haifa), KMC, MAHE, Manipal, Karnataka, India. \\ Corresponding Author: Russell D'Souza \\ Email - russell.f.dsouza@gmail.com
}

The Universal Declaration on Bioethics and Human Rights adopted by the United Nations Educational, Scientific, and Cultural Organisation (UNESCO) on 19 October 2005 was an important step in the search for global minimum standards in biomedical research and clinical practice.

Dag Hjalmar Agne Carl Hammarskjöld, a Swedish economist and diplomat who served as the second Secretary-General of the United Nations (UN) said that the UN was not created to take humanity to heaven but to save it from hell. Although the UN has its weaknesses and limitations, it has an irreplaceable role in the conflictive world by promoting peace, respect for human rights, social and economic development. The UN might be considered imperfect as it often mirrors the world, with its divisions and disagreements. But it is the only forum, where global humanity speaks in its entirety and where it can express, as best as possible, its collective hopes and convictions.

In considering the specific domain of bioethics, Hammarskjo"ld's dictum could be applied to UN agencies that are engaged in this specialty. While these agencies might not be able to guarantee that biomedical advances will always be used for the greatest well-being of humanity, they can at least contribute to prevention of their use in a manner that would be contrary to human dignity and human rights. Among the means UN agencies use to achieve their goals in the promotion of responsible biomedical research and clinical practice, the "standard setting activity" is one of the most salient goal. It is precisely in such a context and with such an expectation that the Universal Declaration on Bioethics and Human Rights was adopted on 19 October 2005, at the 33rd session of the General Conference of UN Education, Scientific, and Cultural Organization (UNESCO), by representatives of 191 countries. It is of importance to note that the drafting process of the declaration, was preceded by a report of an International Bioethics Committee (IBC) working group that initially was mandated to consider the feasibility of such an instrument. The working group, chaired by Professors Leonardo De Castro from the Philippines and Giovanni Berlinguer from Italy, concluded the need to support this initiative and affirmed the need to develop a worldwide common sense to foster understanding and cohesion in relation to new ethical categories and new practical possibilities emerging from the rapid advances in science and technology [1].

With this background in mind, the International Bioethics Committee chaired at the time by Mrs Miche'le Jean from Canada, prepared the preliminary draft declaration. It then took almost 2 years of discussions and public consultations with governmental and non-governmental organisations. Justice Michael Kirby from Australia then further chaired the drafting group, which was open to all IBC members. To ensure transparency in the process, the successive versions of the document were posted on the internet as they were being developed. In January 2005, the draft was examined by the Intergovernmental Bioethics Committee and the final revision took place in two successive meetings of governmental representatives from the member states, who introduced several amendments [2]. 
Despite the great number of existing international guidelines, statements and declarations relating to bioethics, the then new UNESCO Declaration was seen to make its own remarkable contribution to this important area. It is of importance to acknowledge that this declaration was the first international legal, though non-binding, instrument that comprehensively deals with the linkage between human rights and bioethics. Regardless of the weaknesses that is inherent to this kind of instrument, the very fact that virtually all states reached an agreement in this sensitive area is a major achievement. Most international declarations and guidelines in Bioethics do not have the status of legal instruments because they have been issued by nongovernmental organizations such as the World Medical Association (WMA), the Council for International Organizations of Medical Sciences (CIOMS) and other academic or professional institutions. Other documents, although adopted by intergovernmental bodies, cover only specific bioethical issues, such as the UN Declaration on Human Cloning of 2005 [3], and the UNESCO Universal Declaration on the Human Genome and Human Rights of 1997, are regional but not global instruments, such as the European Convention on Human Rights and Biomedicine of 1997.

It is important to indicate that the Declaration includes in its section II, important substantive principles relating to bioethics, such as: Respect for human dignity and human rights (Article 3.1 ), priority of the individual's interests and welfare over the sole interest of science or society (Article 3.2), Beneficence and non-maleficence (Article 4), Autonomy (Article 5, Informed consent (Article 6) and Protection of persons unable to consent (Article 7), special attention to vulnerable persons (Article 8), Privacy and confidentiality (Article 9), Equality, justice and equity (Article 10), Non-discrimination and non-stigmatization (Article 11), Respect for cultural diversity and pluralism (Article 12), Solidarity and cooperation (Article 13), Access to healthcare and essential medicines - Social Responsibility and health (Article 14), Benefit sharing (Article 15), Protection of future generations (Article 16), and Protection of the environment, the biosphere and biodiversity (Article 17).

Section III "Application of the principles" is devoted to principles of a more procedural nature such as: the requirement for professionalism, honesty, integrity and transparency in the decisionmaking process regarding bioethical issues (Article 18), the need to establish independent, multidisciplinary and pluralist ethics committees (Article 19), the call for an appropriate risk assessment and management in the biomedical field (Article 20) and the need for justice in transnational research (Article 21).

\section{THREE BASIC FEATURES OF THE DECLARATION}

Three basic features of the declaration are:

1. The principles of the declaration are formulated in very general terms; the declaration does not give any definition or their precise meaning. This is in keeping the common practice in law, and in conformity with the old maxim in law "Omnis definitio in jure periculosaest", which states every definition in law is perilous. Thus, except for very technical terms, lawmakers normally prefer not to define very precisely most of the words they use. They tend to leave that task to common understanding and, ultimately if necessary, to courts for interpretation, in order not to be constricted in advance by rigid definitions. In the case of the UNESCO Declaration, this strategy is understood also for practical reasons, because it would have been impossible to reach a global agreement on the precise meaning of terms such as "human dignity', "autonomy', "justice', "benefit', "harm" or "solidarity", which have a long philosophical history and are to an extent, conditioned by many cultural factors. Thus, the generality in the formulation of the principles can be justified by the need to find a balance between the universalism of some bioethical norms and the respect for cultural diversity.

2. The second feature of the declaration relates to the nature of UNESCO itself, which is an intergovernmental body. This is relevant and hence this declaration cannot be assessed with purely academic criteria, as this instrument is not the product of academic work but 
is a compromise between a theoretical conceptualization made by experts and what is practically achievable given the political choices of governments. We must remember that governments and not independent experts, have the last word in every declaration or convention issued by UN agencies. This does not mean that the quality of such instruments is necessarily affected negatively by acknowledging the requirements of governments. From the history of the development of the Universal Declaration on Bioethics and Human Rights and the International Bioethics Committee draft was more precise on several points than the final version adopted by governmental representatives. Justice Kirby from Australia himself has admitted, 'Personally, I regret for instance that the recognition of the precautionary principle as a risk management tool for public health purposes had been removed from the final version of the document. On the other hand, I acknowledge that some of the amendments introduced by governmental representatives really enhanced the declaration, such as the more detailed provision regarding research on people unable to consent (Article 7) and the reference to human vulnerability (Article 8)' [4]. Thus, what might be considered is that the approach to bioethics followed by international instruments such as the Declaration on bioethics and human rights is not only an academic but also a political one, and therefore can be assessed with quite different and broader criteria.

3. The third important characteristic of the Universal Declaration on Bioethics and Human Rights is its nonbinding nature. Like any declaration adopted by UN agencies, this UNESCO declaration is part of the so-called 'soft law' instruments - that is, instruments that are weaker than conventions because they are not intended to oblige states to enact enforceable rules inspired by the common standards, but rather serves to encourage them to do so. This methodology allows member states to take on commitments they otherwise would not have taken, because they assume just political obligations that are not legally binding. Furthermore, these soft law instruments do present the advantage of permitting countries to gradually become familiar with the proposed standards before they are confronted with the adoption of enforceable rules or with the development of a binding instrument [5]. It is helpful to remember that, if the same non-binding standards are reaffirmed in successive declarations, over time they are likely to take on the binding rules, in the form of customary law and jurisprudential criteria, as had happened with the Universal Declaration of Human Rights of 1948 [6].

\section{USE OF A HUMAN RIGHTS FRAMEWORK}

Human dignity and human rights, both have features of European enlightenment philosophy, that pervades this Declaration and that the UNESCO chose an ideological framework of human rights that does not feature particularly prominently in professional bioethical analyses [5]. The relevant question is whether the notion that every human being has an inherent dignity and inherent rights makes sense, no matter where this idea originates. One could consider the current widespread conviction that, people have unconditional rights simply by virtue of their humanity and is one of the major achievements of human civilization, much more important than any scientific or technical development. This does not mean one can ignore the fact that in many western nations there has been an excessive emphasis on rights and freedoms for the individual, and this might be considered sometimes to the detriment of family and community values, which are of paramount importance to most non-western societies. The change is that today these controversies have lost much of their practical significance-firstly, because of the increasing number of non-western states that are party to international human rights treaties; secondly, because human rights emerge from international law instruments with enough flexibility to be compatible with full respect for cultural diversity. Far from imposing one cultural standard, human rights instruments set up a minimum protection necessary for human dignity [7-8].

According to Amartya Sen [9], these views are often based on a misconception of non-Western (largely Asian) societies, as if people in these non-western countries had little or no interest in their rights and were only concerned with issues of social order and discipline, a misconception 
which is of course well exploited by authoritarian regimes. Bioethical discourse is linked to human rights and most, international policy documents relating to bioethics issued during the past two decades are framed on a rights-based approach and attach utmost importance to the notion of human dignity. A paradigmatic example in this respect is the Council of Europe's Convention on Human Rights and Biomedicine [10]. Nevertheless, this is not an exclusive feature of Western instruments. Indeed, about 200 worldwide declarations, guidelines, recommendations, opinions and codes relating to bioethics adopted by very different institutions could be cited in support of this assertion [11].

For illustrative purposes, a few examples are be mentioned here. Firstly, the famous WMA Declaration of Helsinki on Research Involving Human Subjects (1964/2000), which refers in explicit terms to the rights of participants and regards the protection of human dignity of research subjects as the first basic principle for medical research, along with respect for their life, health and privacy [12]. Secondly, the UN Commission on Human Rights Resolution 2003/69 of 25 April 2003 entitled "Human rights and bioethics" [13] strongly insists on the need to ensure the protection of human rights in this field and makes a recurring appeal to the "dignity of the human being". Thirdly, the various statements of the ethics committee of the Human Genome Organization (HUGO), which emphasize the need to "adhere to international norms of human rights" and to accept and uphold human dignity and freedom [14].

Why this reliance on human rights to set global bioethical standards? The first obvious reason is that, as biomedical activities deal with the most basic human prerogatives such as the right to life and to physical integrity, it is perfectly sound to have recourse to the umbrella of international human rights law to ensure their protection. Despite all its weaknesses, the existing human rights system, with its extensive body of international standards and wide range of mechanisms, represents a considerable achievement of the current time. Thus, we can understand the use of a human rights framework being used to protect people from harm in the biomedical specialty. A more practical reason for this methodology is that, there are few mechanisms available other than human rights to function as a global ethical foundation [15].

In consideration we can understand that the human rights framework provides a more useful approach for analyzing and responding to modern public health challenges than any framework thus far available within the biomedical tradition [16]. Regarding human dignity, it is reasonable to see it has a key role in international bioethics by providing the ultimate rationale for the norms relating to bioethics [17]. Certainly, the appeal to human dignity in international law is neither new nor specific to the Universal Declaration on Bioethics and Human Rights dealing with biomedical issues. Indeed, this is at the cornerstone of the universal human rights movement that emerged after the Second World War. However, recent international biolaw instruments emphasize the importance of human dignity in a more powerful way than traditional human rights law. Indeed, the contrast between the background role assigned to human dignity in international human rights instruments and the foreground role assigned to it in international bio law could not be more impressive [18].

The UNESCO Universal Declaration on Bioethics and Human Rights inscribes itself in this trend when it places at the top of its principles that of "human dignity, human rights and fundamental freedoms" (Article 3.1) [2]. Similarly, when it provides that "the interests and welfare of the individual should have priority over the sole interest of science or society" (Article 3.2). This provision of Article 3.2 is included, with almost the same wording, in several international documents relating to bioethics, such as the WMA Declaration of Helsinki (Article 5) [18], the European Convention on Human Rights and Biomedicine (Article 2) and the UNESCO Declaration on the Human Genome and Human Rights (Article 10). Through this provision, the UNESCO Universal Declaration on Bioethics and Human Rights attempts to emphasize a direct corollary of the principle of human dignity: that people should not simply become instruments for the benefit of science, because science is not an absolute, but only a means at the service of the human person. It is thus argued that no other bioethical principle could be more fundamental than this one. 


\section{CONCLUSION}

The Universal Declaration on Bioethics and Human Rights is an important step in the search for global bioethical standards. However, in view of the sensitive nature of bioethical issues, the fact that virtually all member states reached a comprehensive agreement in this discipline is a major achievement globally. Most of the declaration's principles are not original; they are derived from several existing international documents. The strength of the Universal Declaration on Bioethics and Human Rights is putting together the bioethics principles and integrating these into a human rights framework. In conclusion the purpose of the declaration was to assemble some basic standards to help the global member states of the UN to promote responsible biomedical research and clinical practice, in conformity with the principles of international human rights law.

\section{REFERENCES}

1. UNESCO IBC. Report on the possibility of elaborating a universal instrument on bioethics, 13 June, 2003.

2. UNESCO 33rd General Conference, Paris, 19 October 2005. http://www.UNESCO.org/bioethics (accessed 4 April 2006).

3. United Nations. Declaration on Human Cloning. GA Res 59/280 of 8 March 2005.

4. Kirby M. UNESCO and universal principles on bioethics: what's next? In: Twelfth session of the International Bioethics Committee (IBC), Abstracts or Texts of the Presentations of Speakers. Paris: UNESCO, 2005, 9-19. http:// www.UNESCO.org/bioethics/

5. Lenoir N, Mathieu B. Les normes internationales de la bioe'thique. Paris: PUF, 1998.

6. United Nations. Universal Declaration of Human Kights. GA Res 217 A (III) of 10 Dec 1948, UN Doc A/810 at 71.

7. Taylor A. Governing the globalization of public health. J Law Med Ethics 2004;32:500-8.

8. Ayton-Shenker D. The challenge of human rights and cultural diversity, United Nations background note. New York: United Nations Department of Public Information, 1995, http://www.un.org/rights/dpi1627e.htm (accessed 4 Apr 2006).

9. Sen A. Universal truths: human rights and the westernizing illusion. Harvard Int Rev 1998;20:403.

10. Andorno R. The Oviedo Convention: a European legal framework at the intersection of human rights and health law. J Int Biotech Law 2005;2:133-43.

11. University of Minnesota Human Rights Library, "Bioethics and Human Rights Links". http://www1.umn.edu/humanrts/links/bioethics.html (accessed 4 Apr 2006).

12. World Medical Association. Declaration of Helsinki on Ethical Principles for Medical Research Involving Human subjects, as amended by the 52nd WMA General Assembly, Edinburgh, October 2000. http://www.wma.net/e/policy/ 103.htm (accessed 4 Apr 2006).

13. United Nations Commission on Human Rights. Resolution 2003/69 on human rights and bioethics of 25 April 2003 (E/CN.4/2003/L.II/Add.7).

14. Human Genome Organisation's (HUGO) Ethics Committee. Statements. http:// www.hugointernational.org/committee_ethics_info.htm. Human Genome Organisation (HUGO) Ethics ommittee. (accessed 4 Apr 2006).

15. Thomasma D. Proposing a new agenda: bioethics and international human rights. Camb Q Health Ethics 2001;10:299-310.

16. Mann J. Health and human rights. Protecting human rights is essential for promoting health. BMJ 1996;312:924-5.

17. Andorno R. La notion de dignite' humaine est-elle superflue en bioe'thique? Revue Ge'ne'r Droit $\mathrm{Me}^{\prime} \mathrm{d} 2005 ; 16: 95-102$.

18. Beyleveld D, Brownsword R. Human dignity in bioethics and biolaw. Oxford: Oxford University Press, 2002.

$* * * * * * * * * * * * * * * * * * * * * * * * * * * * * *$

Acknowledgements-Nil

Source of Funding - Nil

Conflict of Interest $-\mathrm{Nil}$ 